\title{
Use of alternative waste materials in producing ultra-high performance concrete
}

\author{
Shamsad Ahmad* \\ Civil \& Environmental Engineering Department, King Fahd University of Petroleum \& Minerals, \\ Dhahran-31261, Saudi Arabia
}

\begin{abstract}
In a corrosive environment similar to that of the Arabian Gulf, use of high-performance concrete is one of the options to ensure a target service life of concrete structures. However, in absence of good quality coarse aggregates, it is a challenging task to produce high-performance concrete. Recently, the possibility of producing ultra-high-performance concrete (UHPC) has been widely reported in the literature. UHPC is produced without coarse aggregates at very low water to cementitious materials ratio, high amounts of cement, mineral admixtures, and superplasticizer along with fine quartz sand as aggregate, quartz powder as micro-filler, a nd steel fibres for fracture toughness. In the present work, an effort was made to utilize local waste materials as alternative mineral admixtures and local dune sand as aggregate in producing different UHPC mixtures without addition of quartz powder. The mechanical properties, shrinkage, and durability characteristics of the UHPC mixtures were studied. Test results indicate that it is possible to produce UHPC mixtures using alternative waste materials, which would have targeted flow, strength, toughness, and resistance against reinforcement corrosion. The information presented in the paper would help in optimum selection of a mixture of UHPC considering the availability of local materials, exposure conditions and structural requirements.
\end{abstract}

\section{Introduction}

In recent years, the possibility of producing ultra-high-performance concrete (UHPC) has been widely reported in the literature. UHPC is produced without coarse aggregates at very low water to cementitious materials ratio, high cementitious materials content, and quartz fine sand, quartz powder as micro-filler, silica fume or any other suitable mineral admixture, steel or polymer fibres, and high dosage of superplasticizer. UHPC is reported to possess very high strength, elastic modulus, ductility (i.e., fracture toughness), and excellent durability characteristics. The mechanical properties of UHPC typically reported in literature are: compressive strength $>150 \mathrm{MPa}$, flexural tensile strength $>25 \mathrm{MPa}$, modulus of elasticity $>50 \mathrm{GPa}$, and fracture energy $>20000 \mathrm{~J} / \mathrm{m}^{2}[1-4]$.

\footnotetext{
* Corresponding author: shamsad@kfupm.edu.sa
} 
The mixtures of UHPC are developed based on four principles: (i) reduction in porosity through close packing of raw materials and reduction in water/cementitious materials ratio with the help of superplasticizer; (ii) improvement in microstructure through close packing of solid materials, facilitating hydration and pozzolanic reactions, and improving the interfacial transition zone between aggregates and cementitious products; (iii) enhancement in homogeneity by eliminating coarse aggregate and using fine raw materials; (iv) increase in toughness by using fibres. Besides selection of suitable raw materials and mixture design, the mixing methods and curing regimes also significantly affect the quality of UHPC [5].

The specifications regarding ingredients, mix design, mixing methods, and curing of UHPC, as reported in literature, are briefly described in the following sub-sections along with the objectives and significance of the present work.

\subsection{Ingredients}

Fine quartz sand having particles in the size range of 150 to $600 \mu \mathrm{m}$ is used as the only aggregate because coarse aggregate is eliminated from UHPC [2, 3, 5]. Quartz powder having particle size distribution in the range of 0.1 to $100 \mu \mathrm{m}$ is used as micro-filler [2, 3, 5]. If very fine quartz sand is available, the UHPC can be produced without the quartz powder [6]. Ordinary Portland cement with low $\mathrm{C}_{3} \mathrm{~A}$ content, low alkali content, and low to medium fineness is used as primary binder [2, 3, 5]. Silica fume, a byproduct from ferro-silicium industries with particle size distribution ranging from 0.1 to $1.0 \mu \mathrm{m}$ is generally used as mineral admixture $[2,3,5]$. Polycarboxylates are used as most effective superplasticizer for UHPC to achieve the desirable fluidity [7]. Steel fibers having length of $13 \mathrm{~mm}$ and diameter of $0.2 \mathrm{~mm}$ are often used in UHPC mixtures [5].

In addition to cement, silica fume is primarily used as supplementary cementitious materials in UHPC. However, the use of silica fume may not be economical, particularly if it is not available locally at a low price. The partial replacement of cement by locally available cementitious materials would be economical and environment-friendly. The silica fume may be partially or fully replaced and cement may be partially replaced (without compromising with the quality of UHPC) by locally available supplementary cementitious materials such as ground granulated blast furnace slag, fly ash, metakaolin, limestone powder, rice husk, steel slag powder, cement kiln dust, nanomaterials (nano- $\mathrm{SiO}_{2}$, nano- $-\mathrm{CaCO}_{3}$, nano- $\mathrm{Fe}_{2} \mathrm{O}_{3}$, nano- $\left.\mathrm{TiO}_{2}\right)$, etc. $[5,8-14]$.

\subsection{Design of UHPC mixtures}

Particle size distribution, cement content, supplementary cementitious material content, water/cementitious materials ratio, dosage of superplasticizer, and fiber content are the parameters that are optimally selected to satisfy the requirements of UHPC in fresh and hardened states [1, 15-16].

The particle size ranges of cement, supplementary cementitious materials (such as silica fume), fine quartz sand and quartz powder should be selected in such a way that the grading curve for the mixture of granular materials would match with the optimum grading curves, reported in literature, for example optimum grading curve given by Schmidt and Fehling [17] and particle size distribution model for optimization of the composition of mixture of granular materials used for UHPC [18-19].

The values of the mix design parameters can be selected within their ranges as reported in literature [20], as follows: water to total binder ratio 0.15-0.24, cement content 800-1100 $\mathrm{kg} / \mathrm{m}^{3}$, silica fume content $150-300 \mathrm{~kg} / \mathrm{m}^{3}$, silica fume to cement ratio $0.15-0.35$, cement and silica fume content $950-1400 \mathrm{~kg} / \mathrm{m}^{3}$, quartz and sand $1000-1400 \mathrm{~kg} / \mathrm{m}^{3}$, steel fiber content $190-250 \mathrm{~kg} / \mathrm{m}^{3}$. 
In order to obtain an optimum mixture design satisfying the intended fresh and hardened properties of UHPC, various trial mixtures should be considered by choosing different sets of mixture design parameters within their reported ranges satisfying the absolute volume equation, i.e. the sum of absolute volumes of all the ingredients including air content should be equal to the total volume of UHPC considered for mixture design for example $1 \mathrm{~m}^{3}$. After mixture design, the UHPC mixtures should be prepared and tested for flow. The dosage of superplasticizer should be adjusted to keep the flow as $200 \pm 20 \mathrm{~mm}$. Once the required flow for each of the trial mixtures is achieved, the mixtures should be tested for their hardened properties. An optimum mixture of UHPC, out of various trial mixtures considered, should be finally selected based on the high performance at low consumption of cement. UHPC with lower cement content would be economical and environment-friendly because of reduced carbon dioxide footprint.

\subsection{Preparation and curing of UHPC mixtures}

UHPC mixtures are prepared by mixing the ingredients in a proper sequence. First cement, supplementary cementitious materials, sand and filling powder are mixed in dry state for about 10 minutes and then the mixture of water and superplasticizer is added in steps over a period of about 5 to 10 minutes till appropriate flow ability of the mortar matrix is achieved. Finally, the fibers are added [5]. The porosity of an UHPC mixture can be reduced enhancing its hardened properties by using vacuum mixing [21-22]. Various curing regimes reported for producing UHPC include standard room temperature curing for 28 days, heat curing under atmospheric pressure, and autoclave curing [5].

\subsection{Objective and significance of the present work}

The main objective of the present work was to explore the possibility of producing UHPC mixtures utilizing dune sand and several industrial waste materials such as micro silica, natural pozzolana, fly ash, limestone powder, cement kiln dust, and pulverized steel slag, locally available in Saudi Arabia. The outcomes of the present work would be useful in producing UHPC mixtures by concrete industries in Saudi Arabia with a wider range of options regarding the use of readily available raw materials and meeting out the intended strength and durability requirements.

\section{Experimental work}

\subsection{Materials}

The ingredients used to prepare different mixtures of UHPC are listed in Table 1 along with their specific gravities. Locally available dune sand having fine quartz particles was used in its naturally-graded form in all the mixtures. The particle size distribution of the dune sand used in this study is given in Table 2. Due to very fine size range of the dune sand, the quartz powder was not used. A liquid superplasticizer (commercial name: Glenium 51) was used to obtain the desired flow. Glenium 51 is a polycarboxylic ether (PCE) based superplasticizer with $65 \%$ water content by weight that does not contain chlorides and complies with ASTM C494 Types A and F. Varying dosage of this superplasticizer was used to obtain a flow of $200 \pm$ $20 \mathrm{~mm}$ for all the mixtures. Micro copper-coated steel fibres of $0.22 \mathrm{~mm}$ diameter and 13 $\mathrm{mm}$ length with an aspect ratio, $1 / \mathrm{d}$, of 59 were utilized. Fibres are made up of high strength steel (tensile strength greater than $2850 \mathrm{MPa}$ ). Locally available supplementary cementitious materials namely micro silica, natural pozzolana, limestone powder, cement kiln dust, and 
pulverized steel slag were used. The $\mathrm{CaO}$ and $\mathrm{SiO}_{2}$ contents of all cementitious materials used in the present study are presented in Table 3.

Table 1. List of ingredients used for producing UHPC mixtures.

\begin{tabular}{|l|c|}
\hline \multicolumn{1}{|c|}{ Ingredient } & Specific gravity \\
\hline Basic ingredients of UHPC & 1.00 \\
\hline Water & 3.15 \\
\hline Cement (Type I conforming to ASTM C150) & 2.53 \\
\hline Dune sand & 1.09 \\
\hline Superplasticizer (Glenium ${ }^{\circledR}$ 51) & 7.85 \\
\hline Steel fibers & 2.25 \\
\hline Micro silica & \\
\hline Waste materials used to partially replace micro silica and sand \\
\hline Natural pozzolana & 3.00 \\
\hline Fly ash & 2.25 \\
\hline Limestone powder & 1.60 \\
\hline Cement kiln dust & 2.79 \\
\hline Pulverized steel slag & 3.75 \\
\hline
\end{tabular}

Table 2. Particle size distribution of dune sand used.

\begin{tabular}{|c|c|}
\hline Sieve opening, mm & Cumulative \% retained \\
\hline 4.75 & 0 \\
\hline 2.4 & 0 \\
\hline 1.2 & 0 \\
\hline 0.6 & 3.8 \\
\hline 0.3 & 38.6 \\
\hline 0.15 & 78.1 \\
\hline 0.075 & 99.0 \\
\hline
\end{tabular}

Table 3. $\mathrm{CaO}$ and $\mathrm{SiO}_{2}$ contents of the cementitious materials used.

\begin{tabular}{|l|c|c|}
\hline Cementitious material & $\mathbf{C a O}$ content $\mathbf{( \% )}$ & $\mathbf{S i O}_{2}$ content (\%) \\
\hline Cement (Type I) & 64.35 & 22.00 \\
\hline Micro silica & 0.48 & 92.50 \\
\hline Natural pozzolana & 8.06 & 42.13 \\
\hline Fly ash & 8.38 & 45.30 \\
\hline Limestone powder & 45.70 & 11.79 \\
\hline Cement kiln dust & 49.30 & 17.10 \\
\hline Pulverized steel slag & 40.80 & 16.47 \\
\hline
\end{tabular}

\subsection{Design of mixtures}

Design of several trial mixtures of UHPC was carried out considering various design variables, such as water to cementitious material $(w / \mathrm{cm})$ ratio, micro silica content, sand content, and fiber content. Each trial mixtures of UHPC were prepared and tested for flow before casting to test for compressive strength after 28-days of moist curing. Based on a maximum flow of $230 \mathrm{~mm}$ and a maximum 28-day compressive strength of $161 \mathrm{MPa}$, a basic optimum mixture of UHPC (designated as M0) having mixture proportion as follows: $\mathrm{w} / \mathrm{cm}$ ratio $=0.145$ (by mass); cement content $=900 \mathrm{~kg} / \mathrm{m}^{3} ;$ micro silica content $=220 \mathrm{~kg} / \mathrm{m}^{3}$; sand content $=1005 \mathrm{~kg} / \mathrm{m}^{3}$; water content $=162.4 \mathrm{~kg} / \mathrm{m}^{3} ;$ superplasticizer content $=40.3 \mathrm{~kg} / \mathrm{m}^{3}$ ( $3.6 \%$ of the mass of cementitious materials); and steel fiber content $=157 \mathrm{~kg} / \mathrm{m}^{3}$, was selected. 
Taking the basic mixture of UHPC (M0) as a benchmark, various trial mixtures of UHPC were considered by partially replacing micro silica and dune sand using different permutations and combinations of the five waste materials, listed in Table 1, keeping everything same as of mixture M0. These trial mixtures were prepared and tested for flow and 28-day compressive strength and based on adequate flow and maximum 28-day compressive strength, a total of seven optimum mixtures of UHPC with partial replacement of silica fume and dune sand were selected. The details of eight optimally selected UHPC mixtures for detailed study (i.e., M0 without replacement by waste materials and M1 to M7 with replacement by waste materials) are presented in Table 4.

Table 4. Details of eight optimally selected UHPC mixtures for detailed study

\begin{tabular}{|c|c|c|c|c|c|c|c|c|}
\hline \multicolumn{9}{|c|}{$\begin{array}{l}\text { Optimally fixed parameters for all } 8 \text { mixtures: } \mathrm{w} / \mathrm{cm} \text { ratio }=0.145 \text { (by mass); Cement content }=900 \\
\mathrm{~kg} / \mathrm{m}^{3} ; \text { Mineral admixture content }=220 \mathrm{~kg} / \mathrm{m}^{3} ; \text { Water }(\mathrm{w}) \text { content }=162.4 \mathrm{~kg} / \mathrm{m}^{3} ; \text { Superplasticizer } \\
\text { content }=40.3 \mathrm{~kg} / \mathrm{m}^{3}(3.6 \% \text { of the mass of cementitious materials }) ; \text { Steel fiber content }=157 \mathrm{~kg} / \mathrm{m}^{3}\end{array}$} \\
\hline \multirow{2}{*}{$\begin{array}{c}\text { Mixtur } \\
\text { e ID }\end{array}$} & \multirow{2}{*}{$\begin{array}{l}\text { Optimum use of } \\
\text { waste materials in } \\
\text { addition to MS }\end{array}$} & \multirow{2}{*}{$\underset{\left(\mathrm{kg} / \mathrm{m}^{3}\right)}{\mathrm{MS}}$} & \multicolumn{5}{|c|}{ Waste materials $\left(\mathrm{kg} / \mathrm{m}^{3}\right)$} & \multirow{2}{*}{$\begin{array}{c}\text { Sand } \\
\left(\mathrm{kg} / \mathrm{m}^{3}\right)\end{array}$} \\
\hline & & & NP & FA & LSP & CKD & PSS & \\
\hline M0 & Only MS & 220 & - & - & - & - & - & 1005 \\
\hline M1 & $\begin{array}{c}40 \% \text { MS and } 60 \% \\
\text { NP }\end{array}$ & 88 & 132 & - & - & - & - & 1042 \\
\hline M2 & $\begin{array}{l}40 \% \mathrm{MS} \text { and } 60 \% \\
\text { FA }\end{array}$ & 88 & - & 132 & - & - & - & 1005 \\
\hline M3 & $\begin{array}{l}80 \% \text { MS and } 20 \% \\
\text { LSP }\end{array}$ & 176 & - & - & 44 & - & - & 985 \\
\hline M4 & $\begin{array}{l}80 \% \text { MS and } 20 \% \\
\text { CKD }\end{array}$ & 176 & - & - & - & 44 & - & 1015 \\
\hline M5 & $\begin{array}{c}10 \% \text { sand replaced } \\
\text { by LSP }\end{array}$ & 220 & - & - & 87 & - & - & 868 \\
\hline M6 & $\begin{array}{c}5 \% \text { sand replaced } \\
\text { by CKD }\end{array}$ & 220 & - & - & - & 48 & - & 962 \\
\hline M7 & $\begin{array}{c}5 \% \text { sand replaced } \\
\text { by PSS }\end{array}$ & 220 & - & - & - & - & 48 & 972 \\
\hline
\end{tabular}

\subsection{Tests}

Flow test was conducted on each of the eight selected mixtures of UHPC in accordance to ASTM C1437 and subsequently test specimens were prepared to conduct tests for determining their compressive strength, flexural strength, fracture toughness, drying shrinkage, water absorption, DIN water penetration depth, chloride permeability, electrical resistivity, and reinforcement corrosion rate. The details of specimens and test methods used for determining various hardened properties of UHPC mixtures are given in Table 5.

\section{Results and discussion}

The summary of test results are presented in Table 6 . It can be seen from Table 6 that almost all mixtures have satisfied the flow requirements (required range of flow is $180 \mathrm{~mm}$ to 220 $\mathrm{mm})$.

All eight mixtures possess compressive strength above $150 \mathrm{MPa}$. The compressive and flexural tensile strengths and fracture toughness of the UHPC mixtures developed under this 
work are comparable to that of a patented UHPC mixture with a proprietary name Ductal ${ }^{\circledR}$ [24].

Except few mixtures, the shrinkage is in the same range as that for the normal concrete mixtures.

The water absorption for these UHPC mixtures is found to be around one-tenth of the permissible limits for normal concrete. Water penetration depth is zero in all cases indicating negligible water permeability. Chloride permeability and electrical resistivity values for all eight mixtures of UHPC are indicating "very low" to "negligible" risk of reinforcement corrosion. Very low corrosion current densities measured for all the UHPC mixtures (around one-tenth of the threshold value) have confirmed that they are highly corrosion- resistant.

Table 5. Details of specimens and test methods used to determine hardened properties.

\begin{tabular}{|c|c|c|c|}
\hline Property & Specimen shape and size & $\begin{array}{l}\text { Specimens } \\
\text { per } \\
\text { mixture }\end{array}$ & Test method \\
\hline 1. Compressive strength & $50 \mathrm{~mm}$ cube & 3 & ASTM C 109 \\
\hline $\begin{array}{l}\text { 2. Flexural tensile strength } \\
\text { (using } 3 \text { point bend test) }\end{array}$ & $40 \times 40 \times 160 \mathrm{~mm}$ prism & 3 & ASTM C 78 \\
\hline 3. Fracture Toughness & $\begin{array}{c}40 \times 40 \times 160 \mathrm{~mm} \text { prisms } \\
\text { (notched) }\end{array}$ & 3 & $\begin{array}{c}\text { Jenq and Shah } \\
{[23]}\end{array}$ \\
\hline 4. Drying shrinkage & $25 \times 25 \times 275 \mathrm{~mm}$ prism & 3 & ASTM C 356 \\
\hline 5. Water absorption & $75 \times 150 \mathrm{~mm}$ cylinder & 3 & ASTM C 642 \\
\hline 6. Water penetration depth & $100 \mathrm{~mm}$ cube & 3 & DIN 1048 \\
\hline $\begin{array}{l}\text { 7. } \begin{array}{l}\text { Rapid chloride } \\
\text { permeability }\end{array} \\
\end{array}$ & $100 \times 200 \mathrm{~mm}$ cylinder & 3 & ASTM C 1202 \\
\hline 8. Electrical resistivity & $75 \times 150 \mathrm{~mm}$ cylinder & 3 & $\begin{array}{c}\text { Two probe } \\
\text { Wenner method }\end{array}$ \\
\hline $\begin{array}{l}\text { 9. Reinforcement corrosion } \\
\text { rate }\end{array}$ & $\begin{array}{l}\text { A centrally embedded rebar in } \\
75 \times 150 \text { mm concrete } \\
\text { cylinder }\end{array}$ & 3 & $\begin{array}{c}\text { Linear } \\
\text { polarization } \\
\text { resistance method }\end{array}$ \\
\hline
\end{tabular}

Table 6. Summary of test results of eight optimally selected UHPC mixtures

\begin{tabular}{|c|c|c|c|c|c|c|c|c|c|c|}
\hline 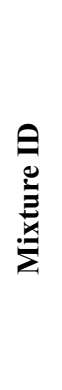 & $\begin{array}{l}\underset{\mathrm{E}}{\mathrm{E}} \\
\frac{\mathrm{z}}{\mathrm{E}} \\
\end{array}$ & 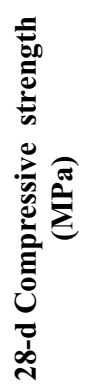 & 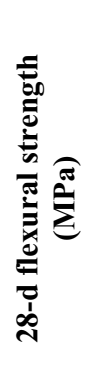 & 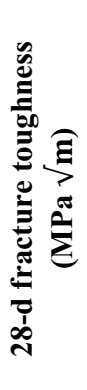 & 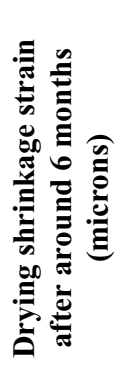 & 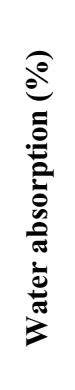 & 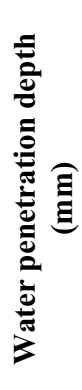 & 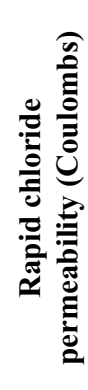 & 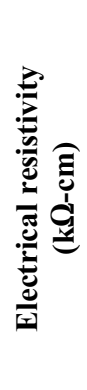 & 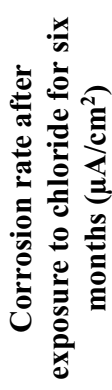 \\
\hline M0 & 230 & 161 & 31 & 8.0 & 450 & 0.43 & 0 & 9 & 179.6 & 0.038 \\
\hline M1 & 195 & 154 & 29 & 5.2 & 845 & 0.62 & 0 & 66 & 205.8 & 0.038 \\
\hline M2 & 210 & 158 & 32 & 6.5 & 446 & 0.40 & 0 & 75 & 110.6 & 0.017 \\
\hline M3 & 255 & 152 & 31 & 4.0 & 594 & 0.40 & 0 & 37 & 245.1 & 0.020 \\
\hline M4 & 220 & 153 & 25 & 4.4 & 585 & 0.35 & 0 & 78 & 182.1 & 0.033 \\
\hline M5 & 215 & 163 & 29 & 4.0 & 867 & 0.32 & 0 & 35 & 313.0 & 0.029 \\
\hline M6 & 180 & 153 & 26 & 4.0 & 1147 & 0.40 & 0 & 75 & 176.8 & 0.039 \\
\hline M7 & 210 & 161 & 24 & 4.5 & 718 & 0.41 & 0 & 49 & 215.4 & 0.026 \\
\hline
\end{tabular}




\section{Conclusions}

Based on the results of the present study, following conclusions can be drawn:

1. The local dune sand and several waste materials available in abundance in Saudi Arabia have potential to produce UHPC mixtures.

2. The local dune sand was found to be naturally well graded cutting the need for quartz powder. Arranging quartz powder for producing UHPC is a big hassle and consumes a lot of time, energy and money.

3. The developed mixtures of UHPC having strength and durability several times more than the normal concrete could be utilized alternatively in special structural members, such as long span bridge girders, large-diameter concrete pipes, heavy-duty tanks, high-rise buildings, precast concrete members etc., and for repairing the deteriorated concrete structures.

The author gratefully acknowledges the financial support received from King Abdulaziz City for Science and Technology (KACST), Saudi Arabia, through King Fahd University of Petroleum \& Minerals (KFUPM), Saudi Arabia, for carrying out this project under the National Science, Technology and Innovation Plan (NSTIP) funding (Project No. AM-08-2009, Code Number: 09-ADV751-04). The technical support received from the Civil \& Environmental Engineering Department and the Center for Engineering Research at the Research Institute, KFUPM, are also acknowledged.

\section{References}

1. F. Larrard, T. Sedran, Cem. Concr. Res., 24(6), 997 (1994)

2. P. Richard, M. Cheyrezy, Cem. Concr. Res., 25(7), 1501 (1995)

3. J. Ma, H. Schneider, Lacer, 7, 25 (2002)

4. G. Moriconi, Proceedings of Jean Pera Symposium on Specialty Cements and Sustainability Issues, 21 (2007)

5. C. Shi, Z. Wu, J. Xiao, D. Wang, Z. Huang, Z. Fang, Constr. Build. Mater., 101, 741 (2015)

6. S. Ahmad, I. Hakeem, M. Maslehuddin, Eur. J. Environ. Civ. En., 20(9), 1106 (2016)

7. Ch. Schröfl, M. Gruber, J. Plank, Cem. Concr. Res., 42(11), 1401 (2012)

8. C. Shi, D. Wang, L. Wu, Z. Wu, Cem. Concr. Compos., 61, 44 (2015)

9. H. Yazıcı, M.Y. Yardımcı, H. Yiğiter, S. Aydın, S. Türkel, Cem. Concr. Compos., 32(8), 639 (2010).

10. H. Yazıc1, H. Yiğiter, A.S. Karabulut, B. Baradan, Fuel, 87(12), 2401 (2008)

11. Yu, R., Spiesz, P. and Brouwers, H.J.H., Cem. Concr. Compos., 55, 383 (2015)

12. Z. Wu, C. Shi, K.H. Khayat, S. Wan, Cem. Concr. Compos., 70, 24 (2016)

13. M.S.M. Norhasri, M.S. Hamidah, A.M. Fadzil, O. Megawati, Constr. Build. Mater., 127, 167 (2016)

14. A. Tafraoui, G. Escadeillas, T. Vidal, Constr. Build. Mater., 112, 980 (2016)

15. K. Sobolev, Cem. Concr. Compos., 26, 901 (2004)

16. C.M. Tam, V.W.Y. Tam, K.M. Ng, Mag. Concr. Res., 62(10), 701 (2010)

17. M. Schmidt, E. Fehling, Proceedings of Seventh International Symposium on the Utilization of High-Strength/High-Performance Concrete, Washington, DC, USA, ACI SP 228, 51 (2005)

18. R. Yu, P. Spiesz, H.J.H. Brouwers, Cem. Concr. Res., 56, 29 (2014)

19. Z.Y. Peng, Ph.D. Thesis, Wuhan University of Technology, China (2009)

20. A. Zubair, M.S. Thesis, King Fahd University of Petroleum \& Minerals, Saudi Arabia (2012) 
21. J. Dils, G.De. Schutter, V. Boel, Mater. Struct., 45(11), 1673 (2012)

22. J. Dils, V. Boel, G.De. Schutter, Mater. Struct., 48(11), 3485 (2015)

23. Y. Jenq, S.P. Shah, J. Eng. Mech., 111, pp. 1227 (1985)

24. Ductal ${ }^{\circledR}$, Chapter 2: Materials and Production. FHWA-HRT-13-060. Virginia, Federal Highway Administration (2013) 